\title{
IDENTIFIKASI JENIS KEPITING BIOLA DI HUTAN MANGROVE DUSUN SETINGGA ASINDESA SEBUBUS KECAMATAN PALOH KABUPATEN SAMBAS
}

\author{
(Identification Species of Fiddler Crabs in Mangrove Forest at Setingga Asin Hamlet Sebubus \\ Village in the Paloh District of Sambas Regency)
}

\author{
Edy Kurniawan, M. Sofwan Anwari, M. Dirhamsyah \\ Fakultas Kehutanan Universitas Tanjungpura Jalan Daya Nasional Pontianak 78124 \\ E-mail: Edyknocks86@yahoo.co.id
}

\begin{abstract}
The fiddler crab is also known as the kepiting biola is an animal that has broad legs that belong to the Crustacean class. Fiddler crab is a type of crab that has a habitat in intertidal areas, especially around mangrove forests and sandy beaches. This study aims to examine the identification of fiddler crab species found in the Mangrove Sebubus. The method used in this research is purposive sampling method with the use of a square plot size of $1 \times 1$ meter as many as 30 pieces in 3 research lines. The results showed as many as 7 species of fiddler crabs found there, that is Uca annulipes, Uca rosea, Uca forcipata, Uca bellator, Uca tetragonon, Uca paradussumieri, and Uca acuta.
\end{abstract}

Keywords: Fiddler Crab, Identification, Mangrove Sebubus

\section{PENDAHULUAN}

Kepiting genus $U c a$ atau yang umum disebut dengan kepiting biola adalah jenis kepiting dari Ordo Decapoda dan termasuk dalam famili Ocypodidae merupakan fauna unik yang berukuran kecil sekitar 2-3 cm. Nama kepiting biola berasal dari cara makan kepiting jantan yang terus menerus bergerak dari substrat ke mulut dan kembali lagi ke substrat mirip dengan gerakan pemain biola saat menggerakkan busur ke biola (capit besar) (Rosenberg, 2000). Kepiting biola merupakan salah satu jenis kepiting yang memiliki habitat di daerah intertidal, terutama di sekitar hutan mangrove dan pantai berpasir. Jumlah kepiting biola yang ada di dunia mencapai 97 jenis, 19 jenis sudah teridentifikasi terdapat di Indonesia.
Aktivitas hidupnya di dalam lubang yang dibuat secara individu dan keluar masuk lubang untuk mencari makan ketika air laut surut dan berdiam di dalam lubang saat air sedang pasang. Kepiting biola yang berusia 12-14 bulan sudah dapat melakukan proses perkembangbiakan dan dalam lingkungan yang mendukung dapat bertahan hidup hingga mencapai umur 3-4 tahun. Satwa ini berperan sebagai pemakan detritus (detrivor) di ekosistem mangrove (Suprayogi, 2014).

Ciri spesifik kepiting biola adalah adanya dimorfisme seksual dan asimetris pada capit yang tidak dimiliki oleh jenis kepiting lainnya (Murniati dan Pratiwi, 2015). Keberadaan dari kepiting biola yang terdapat di daerah ini belum pernah dilakukan publikasi mengenai 
keanekaragaman dan indentifikasi dari kepiting biola tersebut sehingga diperlukan penelitian agar keberadaan kepiting biola dapat terekspos dan diketahui oleh masyarakat luar. Hasil dari riset ilmiah tersebut akan dapat menjadi acuan dan dasar konservasi kepiting biola kawasan daerah tersebut.

\section{METODE PENELITIAN}

Penelitian dilakukan di kawasan Mangrove Desa Sebubus. Mangrove yang terdapat di Desa Sebubus sebagian berupa tegakan alami dan sebagian telah dilakukan penanaman ulang. Terletak di muara sungai besar atau yang biasa disebut sebagai mangrove riparian. Penelitian ini dilakukan 2 minggu efektif di lapangan pada bulan September 2019 di hutan mangrove Dusun Setingga Asin Desa Sebubus Kecamatan Paloh Kabupaten Sambas yang mempunyai luas $\pm 50 \mathrm{Ha}$. Alat dan bahan yang digunakan adalah meteran, binokuler, buku identifikasi kepiting biola (Uca spp.) Kepiting Uca di Hutan Mangrove Indonesia (Murniati dan Pratiwi, 2015), kamera, thermo hygro, refraktometer, soil meter, lux meter, GPS (global positition system).

\section{Pengumpulan Data}

Pengambilan sampel dilakukan pada saat air surut. Penelitian ini dilakukan di 3 jalur dengan panjang $\pm 350 \mathrm{~m}$. Peletakan jalur menggunakan metode line transect dengan jarak antar jalur $\pm 300 \mathrm{~m}$. Setiap jalur akan dibuat 10 buah petak kuadrat yang berukuran 1x1 m dengan jarak antar petak sejauh $35 \mathrm{~m}$. Peletakan petak dilakukan dengan metode purposive sampling, yaitu pengambilan data di lapangan dilakukan secara sengaja dengan melihat keberadaan kepiting biola (Fachrul, 2007). Sampel yang didapat akan dilakukan identifikasi dengan melihat dari warna, capit, dan bentuk corak capit. Identifikasi kepiting biola ini menggunakan buku Kepiting Uca di Hutan Mangrove Indonesia (Murniati dan Pratiwi, 2015) dan Situs Fiddler Crab.

HASIL DAN PEMBAHASAN Jenis Kepiting Biola yang Ditemukan di Kawasan Mangrove Sebubus

Komposisi jenis kepiting biola yang didapat dari tiap jalur pengamatan di kawasan hutan Mangrove Dusun Setingga Asin Desa Sebubus menunjukkan variasi jenis yang berbeda. Berdasarkan hasil pengamatan di lapangan, ditemukan 7 spesies kepiting biola (Tabel 1)

Tabel 1. Rekapitulasi jumlah jenis kepiting biola antar jalur. (Recapitulation of the Number Species of Fiddler Crabs in the Between Lines)

\begin{tabular}{llcccc}
\hline No Sub Genus & Spesies & Jalur 1 & Jalur 2 & Jalur 3 & Total \\
\hline 1 Australuca & Uca bellator & 3 & - & 2 & 5 \\
2 Gelasimus & Uca tetragonon & 12 & 5 & 20 & 37 \\
3 Paraleptuca & Uca annulipes & 18 & 14 & 30 & 62 \\
4 Paraleptuca & Uca paradussumieri & 6 & 8 & - & 14 \\
5 Tubuca & Uca acuta & 42 & 53 & 41 & 136 \\
6 Tubuca & Uca forcipata & 4 & 12 & - & 16 \\
7 Tubuca & Uca rosea & 6 & 7 & - & 13 \\
\hline \multicolumn{2}{c}{ Total Antar Jalur } & 91 & 99 & 93 & \\
\cline { 1 - 3 } \multicolumn{2}{c}{ Total Jenis } & 7 Spesies & 6 Spesies & 4 Spesies & 283 \\
\hline
\end{tabular}


Seluruh jalur pengamatan menunjukkan jumlah spesies yang berbeda beda, hal ini dikarenakan perbedaan faktor lingkungan di ketiga Tabel 2. Data Faktor Lingkungan (Environmental Factor Data)

\begin{tabular}{|c|c|c|c|}
\hline \multirow{2}{*}{$\begin{array}{c}\text { Faktor } \\
\text { Lingkungan }\end{array}$} & \multicolumn{3}{|c|}{ Jalur Pengamatan } \\
\hline & Jalur 1 & Jalur 2 & Jalur 3 \\
\hline Intensitas Cahaya & 2119,67 & 2251,33 & 2209.33 \\
\hline Kelembaban & $79 \%$ & $85 \%$ & $71 \%$ \\
\hline Suhu Tanah & $29^{\circ} \mathrm{C}$ & $28^{\circ} \mathrm{C}$ & $27^{\circ} \mathrm{C}$ \\
\hline Suhu Udara & $32,17^{\circ} \mathrm{C}$ & $29,97^{\circ} \mathrm{C}$ & $31,81^{\circ} \mathrm{C}$ \\
\hline $\mathrm{pH}$ tanah & 5,67 & 5,5 & 5,33 \\
\hline Salinitas & $15,67 \mathrm{ppt}$ & $14 \mathrm{ppt}$ & $13,4 \mathrm{ppt}$ \\
\hline Subtrat & $\begin{array}{c}\text { Lumpur } \\
\text { Avicennia marina }\end{array}$ & $\begin{array}{c}\text { Lumpur } \\
\text { Rhizophora stylosa }\end{array}$ & $\begin{array}{c}\text { Berpasir } \\
\text { Rhizophora apiculata }\end{array}$ \\
\hline Vegetasi & $\begin{array}{l}\text { Rhizophora stylosa } \\
\text { Excoecaria agallocha }\end{array}$ & $\begin{array}{c}\text { Rhizophora apiculata } \\
\text { Nypa fruticans }\end{array}$ & $\begin{array}{c}\text { Xylocarpus granatum } \\
\text { Ceriops decandra }\end{array}$ \\
\hline Kerapatan Vegetasi & Sedang & Tinggi & Sedang \\
\hline
\end{tabular}

Data faktor lingkungan menunjukkan perbedaan antar jalur yang menyebabkan perbedaan spesies yang dijumpai di tiap lokasi penelitian. Menurut Murniati dan Pratiwi (2015) kepiting biola dapat bertahan hidup pada salinitas $20-30 \mathrm{ppt}$ dan suhu $27^{\circ} \mathrm{C}$ $32^{\circ} \mathrm{C}$. Faktor lingkungan juga mempengaruhi populasi serta jumlah individu diseluruh lokasi penelitian. Ketiga jalur menunjukkan jumlah individu yang hampir sama walaupun ketiga jalur memiliki perbedaan antara substrat dan vegetasinya.

\section{Hasil Identifikasi Kepiting Biola di Mangrove Sebubus}

Hasil pengamatan jenis kepiting biola di lapangan menunjukkan bahwa jalur tersebut seperti tutupan vegetasi, salinitas, substrat tanah, dll (Tabel 2), sehingga terjadi perbedaan jumlah jenis di ketiga jalur pengamatan. 


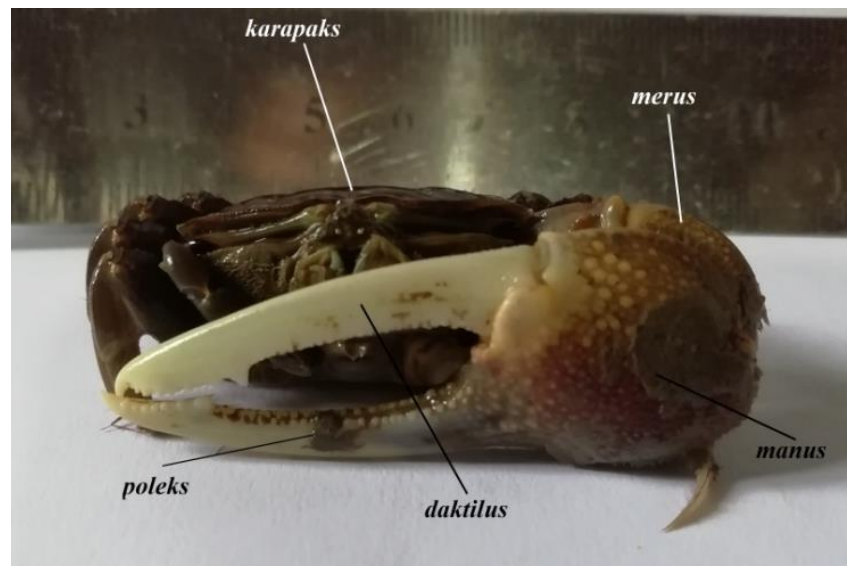

Gambar 1. Individu Uca bellator jantan (Individual Male Uca bellator)

Memiliki karapaks yang berwarna biru gelap dengan bulatan kecil yang berwarna lebih terang serta kaki yang berwarna biru muda, merus hingga manus pada capit besar berwarna biru tua seperti pada bagian karapaks. Bagian dasar manus berwarna keunguan dengan poleks dan daktilus berwarna putih. Ukuran karapaks jantan dewasa sekitar $50 \mathrm{~mm}$. Berdasarkan hasil kajian Murniati dan Pratiwi (2015), kepiting biola hidup di habitat lumpur dan tersebar di Kalimantan, Jawa, Filipina, dan Malaysia.
2. Uca (Gelasimus) tetragonon

Memiliki karakteristik muka yang sempit dengan permukaan manus halus tanpa mimiliki bintil-bintil dan permukaan luar daktilus terdapat alur namun tidak tampak dengan jelas. Bagian poleks tidak terdapat alur, pada bagian dasar poleks terdapat cekungan segitiga yang cukup besar serta daktilus dan poleks yang berbentuk silinder. Kepadatan jenis Uca tetragonon dipengaruhi oleh tingginya frekuensi habitat terendam air (Yulianto, 2006).

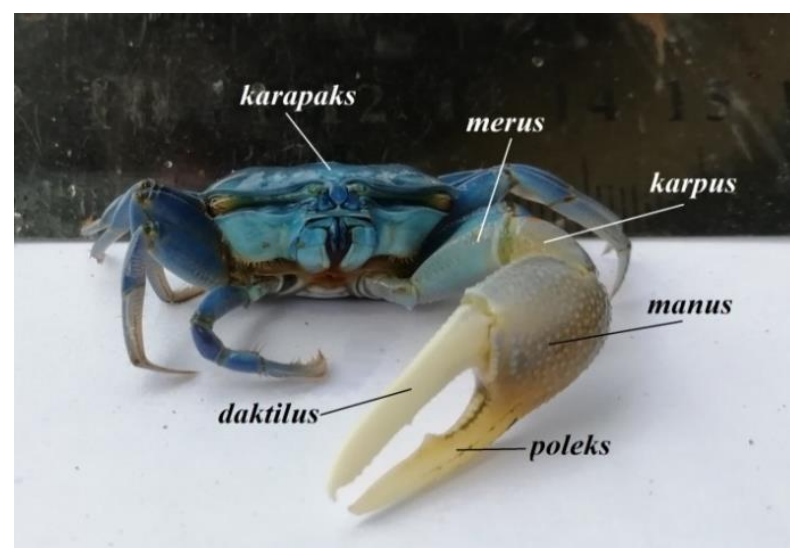

Gambar 2. Individu Uca tetragonon jantan (Individual Male Uca tetragonon)

Karapaks berwarna biru terang dengan corak hitam serta capit besar di bagian poleks dan daktilus berwarna putih dengan manus yang berwarna biru dan berbintik-bintik putih. Murniati dan Pratiwi (2015) menyatakan ukuran karapaks sekitar $50 \mathrm{~mm}$, hidup di daerah yang bersubstrat lumpur serta 
tersebar di seluruh Indonesia, Thailand, Malaysia, Australia, Filipina, Papua Nugini, dan Taiwan.

3. Uca (Paraleptuca) annulipes

Penampakan karapaks pada jenis Uca annulipes terlihat lebar dengan tepi anterolateral yang terlihat jelas serta bagian sudut luar yang tidak menukik. Permukaan manus capit besar terdapat bintil-bintil kecil dan tidak terdapat alur pada bagian sisi luar poleks dan daktilus. Daktilus lebih besar daripada poleks. Memiliki sebuah gigi besar diantara poleks dan daktilus yang terdapat di bagian tengah pada jari jari capit besar dan tidak ada gigi pada bagian capit kecil.

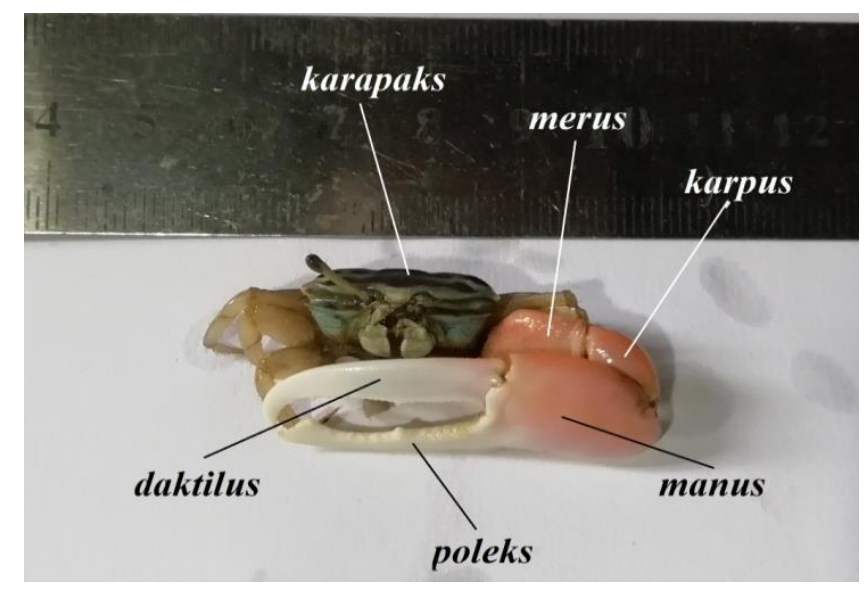

Gambar 3. Individu Uca annulipes jantan (Individual Male Uca annulipes)

Warna karapaks terlihat hitam gelap dengan corak putih bergaris gelombang kasar dengan ukuran berkisar $35-40 \mathrm{~mm}$, bagian merus hingga manus pada capit besar berwarna merah serta poleks dan daktilus yang berwarna putih kemerahan. Murniati dan Pratiwi (2015) mengatakan kepiting biola hidup di substrat berpasir dan tersebar di seluruh pesisir Indonesia, China, Filipina, dan Malaysia.

\section{Uca (Paraleptuca) paradussumieri}

Memiliki bagian lebar pada muka karapaks, tepi anterolateral yang tampak dengan jelas serta orbit yang tidak menukik permukaan manus pada capit terdapat bintilan kasar. Memiliki alur pada permukaan poleks dan daktilus dimana daktilus lebih lebar daripada poleks, pada bagian capit terdapat sebuah gigi besar yang terdapat di bagian tengah capit, tidak terdapat gigi pada permukaan capit kecil. 


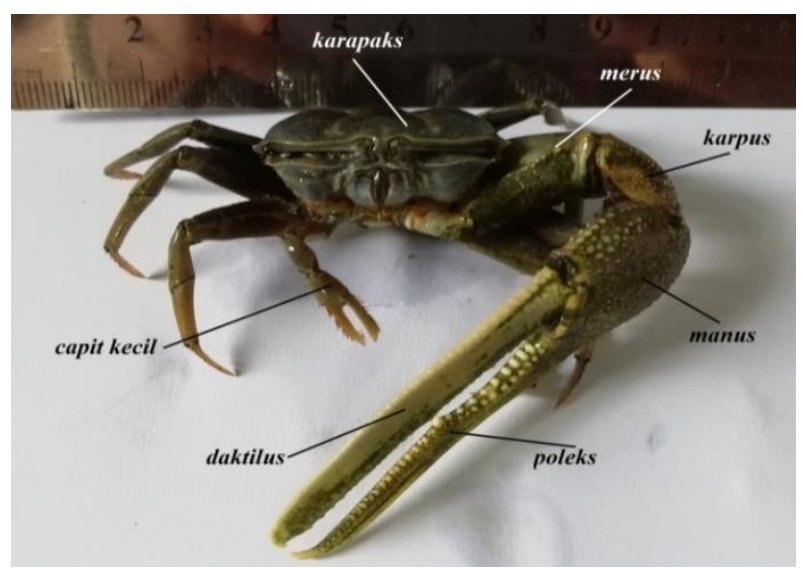

Gambar 4. Individu Uca paradussumieri jantan (Individual Male Uca paradussumieri)

Karapaks berwarna hitam dengan corak cokelat serta poleks dan daktilus pada capit besar berwarna putih kekuningan, memiliki ukuran karapaks sekitar 35-50 mm dan hidup di daerah yang bersubstrat lumpur. Crane (1975) mengatakan kepiting biola tersebar di seluruh Indonesia, Thailand hingga China, Taiwan, Jepang, Filipina, dan Australia bagian timur.

\section{Uca (Tubuca) acuta}

Kepiting biola yang memiliki karakteristik bagian muka karapaks sempit, ukuran panjang tubuh mencapai 20-30 mm, karapaks berbentuk trapesium berwarna hitam dengan corak putih melintang dekat anterior. Manus, karpus, merus berwarna hitam keunguan, sedangkan daktilus dan poleks berwarna putih, dengan gigi mendekati ujung daktilus. Permukaan pada bagian karapaks dan capit bertekstur halus. Tangkai mata yang panjang dan bintik matanya berwarna merah.

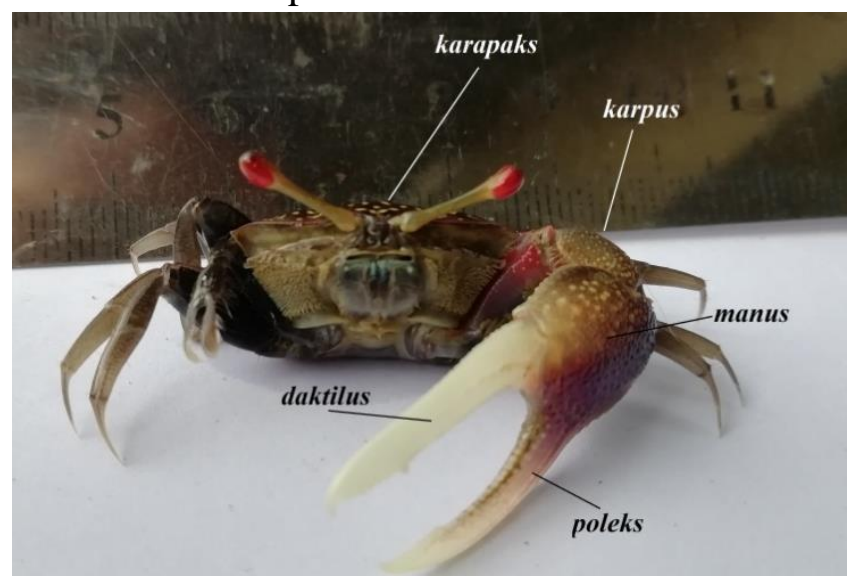

Gambar 5. Individu Uca acuta jantan (Individual Male Uca acuta)

Menurut Crane (1975), Uca acuta hidup pada substrat lumpur dan banyak ditemukan didaerah mangrove dengan kondisi lumpur yang rata di pinggir muara sungai. Sebaran jenis Uca ini di Indo-Pasifik Barat dan China.

6. Uca (Tubuca) forcipata 
Memiliki kenampakan karapaks yang sempit, dasar orbit berbintil pada betina dengan tepi anterior yang hampir lurus dan tepi anterolateral tampak jelas dan miring serta memanjang ke bagian dalam posterior karapaks. Bagian dalam manus capit besar terdapat bintil-bintil yang berukuran cukup besar, pada bagian luar poleks dan daktilus terdapat sebuah alur. Ujung poleks dan daktilus tidak memiliki bentuk khusus, dimana kaki ke empat jenis ini cukup panjang dan pada capit kecil dilengkapi dengan gigi kecil.

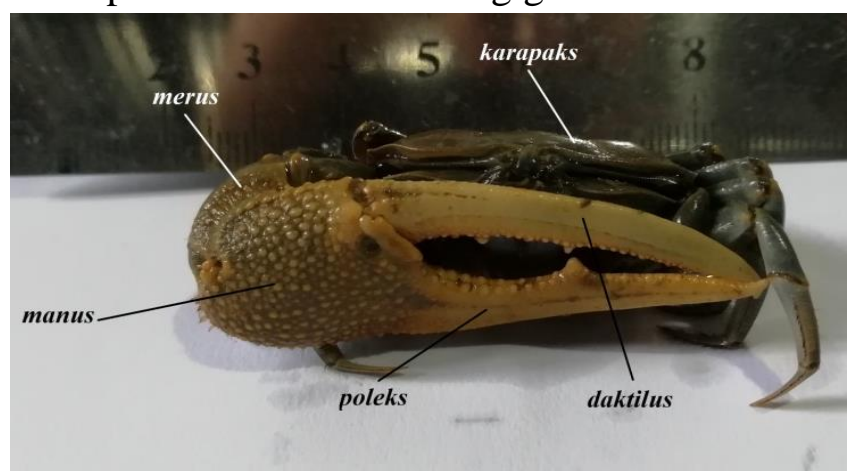

Gambar 6. Individu Uca forcipata jantan (Individual Male Uca forcipata)

Memiliki karapaks yang berwarna hitam dengan corak putih, poleks dan daktilus pada capit berwarna putih kekuningan sedangkan manus berwarna cokelat, memiliki ukuran karapaks sekitar 30-50 mm. Murniati dan Pratiwi (2015) menjelaskan bahwa kepiting biola hidup di daerah bersubstrat lumpur dan memiliki persebaran di daerah Kalimantan, Jawa, pesisir barat daya Sulawesi, Thailand, dan Malaysia.

7. Uca (Tubuca) rosea
Karakteristik dari Uca rosea memiliki permukaan karapaks yang sempit dengan dasar orbit berbintil hanya pada betina sedangkan jantan tidak memilikinya. Permukaan bagian luar manus capit besar dilengkapi dengan bintil-bintil kecil dimana bintil terbesar dekat dengan daerah daktilus yang hampir berbentuk segitiga, tidak memiliki jalur pada permukaan poleks, tepi dorsal lurus, bagian capit kecil bergerigi dan tepi dorsal dan daktilus dilengkapi dengan setae.

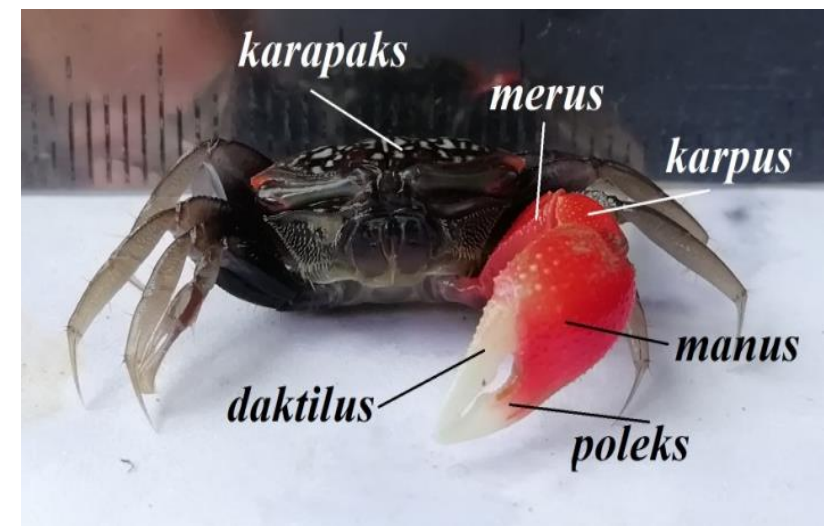

Gambar 7. Individu Uca rosea Jantan (Individual Male Uca rosea) 
Karapaks berwarna coklat dengan corak putih serta manus, karpus, dan merus berwarna merah. Poleks, dan daktilus berwarna putih. Murniati dan Pratiwi (2015) menyatakan ukuran karapaks sekitar 20-30 mm, hidup di daerah yang bersubstrat lumpur dan tersebar di daerah Sumatra, Kalimantan Barat, bagian barat India hingga Malaysia, dan Singapura.

\section{KESIMPULAN}

Kawasan mangrove sebubus memiliki potensi yang cukup tinggi sebagai habitat kepiting biola. Spesies kepiting yang terdapat di lokasi penelitian kawasan mangrove Dusun Setingga Asin Desa Sebubus Kecamatan Paloh Kabupaten Sambas berjumlah 7 spesies yang terdiri dari Uca annulipes, Uca rosea, Uca forcipata, Uca bellator, Uca tetragonon, Uca paradussumieri, dan Uca acuta, yang tergolong kedalam 4 sub genus yaitu Paraleptuca, Tubuca, Australuca, dan Gelasimus,

\section{SARAN}

1. Perlu dilakukan kebijakan terkait kawasan mangrove dan sekitarnya demi menjaga kelestarian mangrove sehingga akan turut melindungi flora dan fauna yang terdapat di dalamnya.

2. Perlunya penelitian secara berkala menhgenai kepiting biola untuk mengetahui peningkatan maupun penurunan spesies kepiting biola di kawasan mangrove sebubus.

\section{UCAPAN TERIMA KASIH}

Ucapan terima kasih penulis ucapkan kepada seluruh pihak terkait yang telah membantu seluruh kegiatan penelitian ini, terkhusus untuk pembimbing dan penguji serta pengurus mangrove sebubus beserta teman-teman seperjuangan.

\section{DAFTAR PUSTAKA}

Crane J. 1975. Fiddler Crabs of the Word Ocypodidae: Genus Uca. Princtown University press. New Jersey.

Fachrul 1MF. 2007. Metode Sampling Ekologi. Jakarta: Bumi Aksara.

Murniati DC dan Pratiwi R. 2015. Kepiting Uca di Hutan Mangrove Indonesia: Tinjauan Aspek Biologi dan Ekologi untuk Eksplorasi. Jakarta:LIPI Press.

Macintosh DJ. 1984. Ecology and Productivity of Malaysian Mangrove Crab Populations (Decapoda: Brachyura). Dalam Prosiding Simposium Mangrove Environment - Restoration \& Management, 1984: 354-377.

Rosenberg MS. 2000. The Comparative Claw Morphology, Phylogeny, and Behavior of Fiddler Crabs (Genus Uca). Ph.D. Thesis. Department of Ecology and Evolution, State University of New York at Stony Brook, Stony Brook, NY.

Suprayogi D. 2014. Keanekaragaman Kepiting Biola (Uca spp) di Desa Tungkal I Tanjung Jabung Barat. Biospesies. 7 (1) : 22-28

Yulianto A. 2006. Keanekaragaman Kepiting di Hutan Mangrove Desa Tungkal Tanjung Jabung Barat. Jambi. Bogor:Institut Pertanian Bogor. 